\title{
Comparison of allocation approaches in soybean biodiesel life cycle
} assessment

\author{
S. Morais, A. A. Martins and T. M. Mata
}

ABSTRACT

This work shows the influence of using different allocation approaches when modelling the inventory analysis in a soybean biodiesel life cycle assessment (LCA). Results obtained using mass, energy and economic based allocations are compared, focusing on the following aspects: normalised potential environmental impact (PEI) categories, total PEI and relative contributions to the total PEI from each life cycle stage and environmental impact category. Similar results are obtained either using economic and energy based allocations. However, different results are obtained when mass based allocation is used when compared with the other two. This study also illustrates that using different allocation approaches in biodiesel LCA may influence the final conclusions, especially in comparative assertions, emphasising the need to perform a sensitivity analysis in the LCA interpretation step.

Keywords: Allocation approaches, Mass based allocation, Economic based allocation, Energy based allocation, Life cycle assessment, Soybean biodiesel

\section{Introduction}

The choice of an adequate allocation approach to model the inventory analysis in life cycle assessment (LCA) studies is still a contentious subject. Allocation can be defined as the partitioning or assignment of material inputs and environmental releases or outputs among the main products, coproducts, byproducts and wastes in a multioutput process. ${ }^{1}$ For purpose of this article, coproducts are defined as products with economic revenues similar to the main product, byproducts are defined as products with lower revenues than the main product and waste is defined as a material that provides little or no revenue. ${ }^{1}$ The environmental burdens are assigned to them according to weighting factors, designated as 'allocation factors', representing the pro- portion of an output relatively to the other. Those quantities can be based on the mass flow, or the energy value, or the economic revenue of products. In most studies, allocation factors are determined on an arbi-

trary basis since harmonised and widely accepted procedures to define which allocation approach is the most adequate are still not available.

Documents commonly seen as standard references endorse the use of different allocation procedures. ${ }^{2}$ For example, the US EPA guidance ${ }^{3}$ recommends a mass based allocation, while the GREET model ${ }^{4}$ follows an energy based allocation, and the CML guide ${ }^{5}$ advocates an economic based allocation. The choice of an adequate allocation approach appears to be more based on the practitioner's preferences than on a logically comprehensible theory. ${ }^{2}$ However, as stated by Weidema, in a LCA study, such an arbitrary choice may significantly influence or determine the final results. ${ }^{6}$

Allocation can be avoided altogether using a system expansion approach, considered by ISO $14041^{7}$ as the preferred method and the more correct scientifically. ${ }^{8,9}$ In a system expansion perspective, it is, for example, subtracted to a given main product ' $A$ ' the environ- mental burdens of an alternative route for producing the coproduct ' $B$ '. The main product ' $A$ ' generates a credit equal to the credit saved by not producing the material that the coproduct ' $B$ ' is most likely to displace. The main difficulty with this approach is to find exact substitutes to coproducts. To illustrate this idea, one may consider the soybean biodiesel life cycle in which the soybean oil extraction process originates soybean meal as a coproduct. Soybean meal can be used as cattle foodstock, like rape meal, corn meal or dried distiller grain, but they are not exact substitutes of the former because of their different metabolised energies. 10 Moreover, the multiple choices for product replacement generate a set of credit values that can be assigned to the primary product. Thus, it is clear that this choice can also significantly influence the final results.

In biodiesel LCA studies, the use of an allocation approach seems to be preferable instead of using a system expansion approach, and it was adopted by several practitioners mainly due to its simplicity. For example, Sheehan et al. ${ }^{11}$ applied a mass based allocation approach, Elasayed et al. ${ }^{12}$ and Zah et al. ${ }^{13}$ employed economic based allocation procedures and Hill et al. ${ }^{14}$ an energy based allocation. Other authors assessed the influence on the final results of using different allocation approaches, although focusing on specific aspects such as the emission of greenhouse gases (GHG) or the energy requirements. For example, 

Bernesson et al. ${ }^{15}$ carried out a limited LCA study to compare different rape methyl ester production plant scales, using energy and economic based allocations. Results showed that both GHG emissions and energy use are higher if an economic based allocation is applied instead of an energy based allocation. On the other hand, Hou et al. ${ }^{16}$ performed an LCA study to compare GHG emissions and energy use of soybean biodiesel and other renewable fuels with conventional petroleum based fuels, showing similar results for the energy and economic based allocations.

The differences between the studies of Bernesson et al. ${ }^{15}$ and Hou et al. ${ }^{16}$ arise not only from the different vegetable oils considered but also on the assumptions used when performing the energy based allocation approach. For example, while Bernesson et al. ${ }^{15}$ considered the heating value of rapeseed meal to be used as fuel, Hou et al. ${ }^{16}$ used the nutrition calorific value of soybean meal that can be metabolised by chicks.

In this work, a soybean biodiesel LCA is undertaken, in a similar manner to the studies of Bernesson et al. ${ }^{15}$ and Hou et al., 16 but performing a more extensive environmental impact assessment. The following potential environmental impact (PEI) categories are utilised, as proposed by Guine'e et al.: ${ }^{17}$ global warming, stratospheric ozone depletion, non-carcinogenic and carcinogenic human toxicological effects, photo-oxidation potential, freshwater and marine aquatic ecotoxicity, terrestrial ecotoxicity, acidification, aquatic eutrophication, terrestrial eutrophication, non-fossil abiotic resources depletion and fossil abiotic resources deple- tion. In addition, land use is considered in this study as an impact category due to the agricultural origin of the soybean biodiesel feedstock. The influence of the three different allocation approaches (mass, energy and economic based allocations) in the soybean biodiesel LCA study is analysed, and results are compared.

Study scope and inventory analysis

Functional unit

The functional unit selected for this study is $1 \mathrm{MJ}$ of usable energy from a vehicle engine driveshaft.

\section{System boundary definition}

This study considers the soybean biodiesel life cycle from a 'well-to-wheel' perspective. Figure 1 presents the life cycle stages, process units and the inputs and outputs crossing the system boundary. Processes related to road infrastructure, vehicle manufacture and maintenance and vehicle end of life management are not considered within the system boundary. In Fig. 1, the dashed line represents the life cycle stages of soybean biodiesel for which it is considered the infrastructure, energy, auxiliary and raw materials, waste disposal, air and wastewater treatment. The continuous line represents the system boundary including all the processes considered for the inventory analysis. The transportation among all the life cycle stages is considered in the system boundary.

\section{Inventoryanalysis}

\section{Soybean agriculture}

The inventory data considers the environmental flows from soybean cultivation, fertiliser production and use (phosphate, potash and nitrogen), electricity generation,

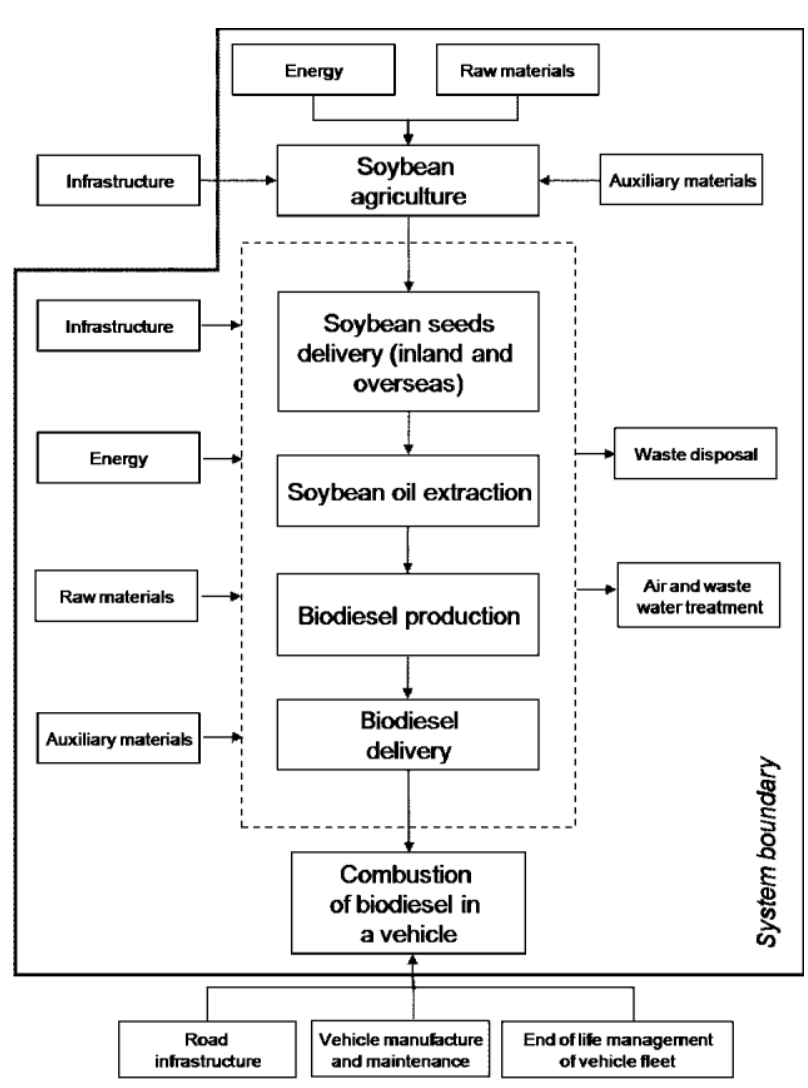

1 System boundary definition for soybean biodiesel life cycle

and natural gas, propane, gasoline, diesel and agrochemicals consumption. Data for the soybean agricul- ture life cycle stage is obtained from Sheehan et al. ${ }^{11}$

The infrastructure construction and operation is not accounted for, since Frischknecht et al. ${ }^{18}$ estimated that the contribution of capital goods in agriculture products and processes is $-2 ? 6 \%$ of their total environmental load. Thus, it was assumed as negligible.

\section{Soybean oil extraction}

The inventory data for the soybean oil extraction takes into consideration the inputs/outputs from soybean crushing, solvent ( $n$-hexane) production, electricity production and steam and natural gas production. For the first two processes, data were obtained from Sheehan et $a .^{11}$ and for the remaining processes from Frischknecht. ${ }^{19}$ From the oil extraction process, soybean meal is obtained as a coproduct.

\section{Biodiesel production}

Soybean oil is converted into biodiesel through an alkali catalysed transesterification reaction, using methanol as reagent and producing glycerol as a byproduct. The inventory data for the biodiesel production considers inputs/outputs from steam production, electricity production, methanol $(\mathrm{CH} 3 \mathrm{OH})$ production, sodium methoxide $\left(\mathrm{CH}_{3} \mathrm{NaO}\right)$ production, sodium hydroxide $(\mathrm{NaOH})$ production, hydrogen chloride productionand soybean oil conversion to biodiesel in a mixed chemical reactor.

Inventory data for the transesterification process is obtained from Sheehan et al. ${ }^{11}$ Inventory data for background processes was obtained from Sheehan et al. ${ }^{11}$ for the methanol, sodium hydroxide and methoxide productions; from Frischknecht ${ }^{19}$ for the 
steam and electricity production and from BUWAL 20 for the remaining data.

\section{Transportation within biodiesel life cycle stages}

It is assumed that soybean is produced in the USA and that soybean seeds are exported to Europe in an ocean freighter. A distance of $195 \mathrm{~km}$ is estimated for biodiesel distribution in an intercity truck (16 ton). For the inventory analysis, it was considered a transportation efficiency of $50 \%$, which means that the truck leaves the production unit fully loaded and returns fully empty. In other words, this value means that the truck is in average half loaded the entire trip in both ways. Inventory data for transportation was obtained from Frischknecht. ${ }^{19}$ The transportation steps in the background processes (e.g. methanol production) were not considered in the inventory analysis.

\section{Biodiesel combustion in vehicle engine}

In this study, the tailpipe emissions from burning biodiesel in a heavy duty vehicle were described as done by Beer et $a^{2}{ }^{21}$ In this study, the absence of carbon derived from fossil fuels on tailpipe emissions of soybean biodiesel burning is assumed, although methanol che- mically coupled to the fatty acids from vegetable oil contains fossil carbon. Thus, all the $\mathrm{CO}_{2}$ released during the biodiesel combustion is assumed to be recycled back in the soybean agriculture stage. However, Sheehan et al. ${ }^{11}$ estimates that 94 ? $8 \%$ of the total $\mathrm{CO}_{2}$ emitted at the tailpipe has a biomass origin, and it is recycled in the agriculture step of the life cycle for biodiesel, assuming that biomass carbon and fossil carbon partition equally among the carbon containing combustion products (CO, $\mathrm{HC}$ and $\mathrm{PM})$.

\section{Allocation approaches}

Soybean oil extraction and biodiesel production are multioutput processes for which material inputs and outputs, including environmental releases, have to be assigned to the main products, coproducts and bypro- ducts during the inventory analysis. In order to assign process inputs and outputs or environmental burdens among soybean oil and soybean biodiesel, three alloca- tion approaches were considered: mass, energy and economic based allocations. Each one will be described in detail in the following sessions.

\section{Mass based allocation}

In a multi-output process, mass based allocation is based on the simple measure of the valuable product output mass flow proportions either as main products, coproducts or byproducts. Then, the part of the global emissions and energy consumption in the life cycle corresponding to each product is equal to its percentage in the overall products. For example, the inventory data of the transesterification process (i.e. the foreground data from biodiesel production) includes $82 ? 40 \%(w / w)$ of biodiesel (product), $17 ? 54 \%(w / w)$ of glycerol

Table 1 Price data applied in economic based allocation (coproduct) and $0 ? 06 \%(\mathrm{w} / \mathrm{w})$ of residual soapstock (waste). Thus, considering that the valuable products are biodiesel and glycerol, the overall environmental bur- dens of this process are assigned to them by allocation factors of 82 ? $45 \%$ and 17 ?55\% for biodiesel and glycerol respectively. Note that the classification of a product as coproduct or byproduct according to the 'Introduction' section does not have an influence on the calculation of the allocation factors.

\section{Energybasedallocation}

Energy based allocation may be applied using the calorific value as an allocation basis when products have energy or food values. ${ }^{14,16,22}$ Soybean meal is widely used as feed to dairy and beef cattle, although the measurement of the caloric nutritional value in food as a proxy of energy in a fuel context is controversial. ${ }^{23}$ The energy allocation factor of a main product or coproduct is calculated on the basis of its produced quantity times its energy content and then divided by the total energy content of the valuable main product and coproduct(s). In the present study, the soybean meal metabolisable energy content for chick of 11 ?59 $\mathrm{MJ} \mathrm{kg}^{-124}$ and the lower heating value of 39 ? $62 \mathrm{MJ} \mathrm{kg}^{-1}$ for soybean oil were considered. ${ }^{25}$ Note that being an animal food rather than a fuel, the energy value of soybean meal is measured as the energy released when it is digested, as proposed by Hou et al. ${ }^{16}$

The expected increase of biodiesel production will lead to a decrease in the glycerol market value due to oversupply. Eventually, it will become a waste product if no other valuable applications for the glycerol worked out in the near to medium term. Within this scenario, the use of glycerol as fuel in industrial processes, due to its heating value, can be seen as a viable final destination for it. In this perspective, the lower heating value of crude glycerol (25?30 $\mathrm{MJ} \mathrm{kg}^{-1}$ ) was used in this study for the energy allocation factors calculation. ${ }^{26}$ For soybean biodiesel, it was used with its lower heating value of 39 ? $76 \mathrm{MJ} \mathrm{kg}^{-1}$. 25

\section{Economic based allocation}

Economic based allocation is a measure of the incomes that may result from trading the process valuable products at market price. It is calculated on the basis of the products' economic value, i.e. the quantity pro- duced times their price relatively to the total products revenue. The proposed solution from Guine'e et al. ${ }^{17}$ to use three consecutive annual price averages (2006-2008) was followed. Table 1 shows the price data used in this study for the economic based allocation.

\section{Allocation factors for this study}

As described above, the mass, energy, and economic based allocation factors for the multi-output processes considered in this study (soybean oil extraction and biodiesel production) were calculated. These are presented in Table 2.

\begin{tabular}{|c|c|c|}
\hline Process & Economic flow & Price, $J / k g$ \\
\hline Soybean oil extraction & Soybean oil & $\begin{array}{l}0 \cdot 486 \\
\text { http://futures.tradingcharts.com Soybean meal } \\
0 \cdot 139 \\
\text { http://futures.tradingcharts.com }\end{array}$ \\
\hline Biodiesel production & Soybean biodiesel & $1 \cdot 340$ \\
\hline
\end{tabular}


Table 2 Mass, energy and economic based allocation factors for soybean oil extraction and biodiesel production processes

Process/products, coproductsand byproducts
Mass based

allocation,

$\%$
Energy based

allocation,

$\%$
Economic based allocation, $\%$

\begin{tabular}{llrr}
\hline Soybean oil extraction & 16.97 & 41.13 & $41 \cdot 67$ \\
Soybean oil & 83.03 & 58.87 & 58.33 \\
Soybean meal & & 88.07 & $91 \cdot 30$ \\
Biodiesel production & 82.45 & 11.93 & 8.70 \\
Soybean biodiesel & 17.55 & & \\
Glycerol & &
\end{tabular}

As shown in Table 2, the energy and economic based allocation factors are up to 2 ? 4 times higher than the mass based allocation factors for the soybean oil product.

The energy and economic based allocation factors for soybean meal and soybean oil are quite similar. This may be the result of the proportionality usually verified between a product energy value and its market value. For biodiesel production, differences in the allocation factors among the three approaches are less significant

than for the oil extraction process.

Potential environmental impacts assessment Classification and characterisation

In the classification step, the inventory inputs and outputs (substances/resources) are imputed to impact categories. Then, the characterisation step follows in which the PEI categories are determined using the

Table 3 Applied impact category assessment models several impact assessment models presented in literature (shown in Table 3).

\section{Normalisation and aggregation}

In the normalisation step, the normalised PEI categories $N_{k}$ are calculated according to equation (1) by dividing each PEI category $S_{\mathrm{k}}$ by its reference PEI value $R_{\mathrm{k}}$, which is calculated considering a geographical location for

$$
N_{\mathrm{k}}=\frac{S_{\mathrm{k}}}{R_{\mathrm{k}}}
$$

particular reference year. ${ }^{38}$

Table 4 presents the reference PEI values $R \mathrm{k}$ applied in this study that are calculated using, as reference, the year 1995 (except year 1996 for terrestrial euthrophication) and the geographical locations of Western Europe or EU-15.

In order to assess how the different allocation approaches influence the total PEI evaluation, the

\begin{tabular}{|c|c|c|c|}
\hline PEl category & Model & Category indicator basis & References \\
\hline Global warming (kg CO2 eq) & IPCC'sGWP & Global warming potentials & $\mathrm{IPCC}^{27}$ \\
\hline $\begin{array}{l}\text { Stratospheric ozone } \\
\text { depletion (kg CFC-11 eq) }\end{array}$ & WMO's ODP & Ozone depletion potentials & $\mathrm{WMO}^{28}$ \\
\hline $\begin{array}{l}\text { Non-carcinogenic human } \\
\text { toxicological effects (DALY) }\end{array}$ & USES-LCA2·0 & $\begin{array}{l}\text { Hazard equivalents using } \\
\text { multimedia fate and } \\
\text { multipathway exposure } \\
\text { modelling with policy based }\end{array}$ & Huijbregts et al. ${ }^{29,30}$ \\
\hline Carcinogenic human toxicological & USES-LCA2.0 & & Huijbregts et al. ${ }^{29,30}$ \\
\hline effects (DALY*) & USES-LCAL: & $\begin{array}{l}\text { multimedia fate and } \\
\text { multipathway exposure } \\
\text { modelling with policy based } \\
\text { toxicological thresholds }\end{array}$ & \\
\hline $\begin{array}{l}\text { Photo-oxidant formation (YOLL }\{\text { ) } \\
\text { ozone }\end{array}$ & EcoSense & Increase of ground level & Krewitt et al. 31 \\
\hline $\begin{array}{l}\text { Freshwater aquatic } \\
\text { ecotoxicity (1,4-DCB eq) }\end{array}$ & USES-LCA & $\begin{array}{l}\text { formation } \\
\text { Hazard equivalents for } \\
\text { species in surface waters }\end{array}$ & Huijbregts et al. ${ }^{32}$ \\
\hline $\begin{array}{l}\text { Marine aquatic } \\
\text { ecotoxicity }(1,4-D C B \text { eq) }\end{array}$ & USES-LCA & $\begin{array}{l}\text { Hazard equivalents for } \\
\text { species in oceanic waters }\end{array}$ & Huijbregts et al. 32 \\
\hline Terrestrial ecotoxicity (1,4-DCB eq) & USES-LCA & $\begin{array}{l}\text { Hazard equivalents for species } \\
\text { in soils }\end{array}$ & Huijbregts et al. ${ }^{32}$ \\
\hline $\begin{array}{l}\text { Acidification (1,4-DCB eq) } \\
\text { capacity }\end{array}$ & EPS version 2000 & Increase of base cation & Steen 33,34 \\
\hline Aquatic eutrophication $\left(\mathrm{kg} \mathrm{PQ}^{2} \mathbf{\{}\right.$ eq) & EPS version 2000 & $\begin{array}{l}\text { of soils } \\
\text { Several effects (increased fish } \\
\text { production capacity, contribution } \\
\text { to species extinction) }\end{array}$ & Steen 33,34 \\
\hline Terrestrial eutrophication (kg wood) & RAINS-LCA & Spatial dependent eutrophication & \\
\hline
\end{tabular}


entials for air emissions, taking fate, background depositions andeffects into account

Land use (PDF $\mathrm{m}^{2}$ year $/ \mathrm{m}^{2}$ ) disappeared

Eco-Indicator 99

Increase of potentially

fraction (PDF) of vascular plant

species

Eco-Indicator 99

Ore concentration trends
Huijbregts et al. ${ }^{35}$

Goedkoop and

Spriensma 36,37

Goedkoop and
Spriensma 36,37

depletion ( $\mathrm{kg}$ antimony eq)

*DALY: disable adjust life years.

\{YOLL: years of life lost. 
Table 4 Reference PEl categories $R \mathrm{k}$ for Western Europe and EU-15

\begin{tabular}{|c|c|c|}
\hline Reference PEI category & $R \mathrm{k}$ & Reference \\
\hline 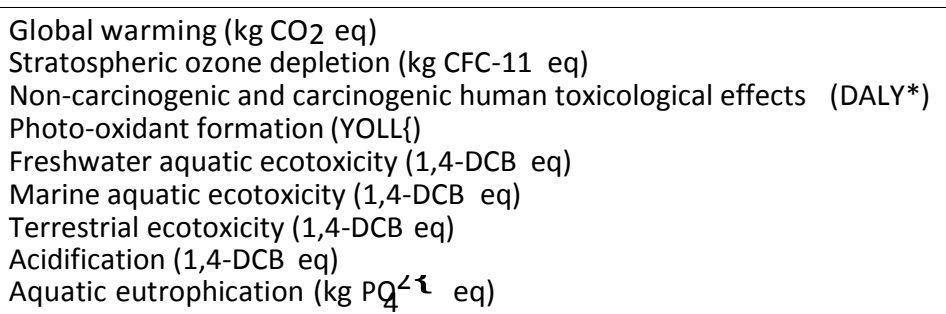 & $\begin{array}{l}4 \cdot 8125610^{12} \\
8 \cdot 3000610^{\prime} \\
3 \cdot 2092610^{\mathrm{O}} \\
1 \cdot 4164610^{\perp 4} \\
5 \cdot 0500610^{\perp 1} \\
1 \cdot 1000610^{\perp 4} \\
4 \cdot 7000610^{\perp 4} \\
3 \cdot 5005610^{\perp 4} \\
1 \cdot 4642610^{<L}\end{array}$ & $\begin{array}{l}\text { EU-15, } 1995\{ \\
\text { Western Europe, } 1995^{\text {sy }} \\
\text { Western Europe, } 1995^{\text {s }} \\
\text { EU-15, } 19951 \\
\text { Western Europe, } 1995^{\text {sy }} \\
\text { Western Europe, } 1995^{\text {sy }} \\
\text { Western Europe, } 1995^{\text {sy }} \\
\text { EU-15, 1995" } \\
\text { Western Europe, } 1995^{\text {sy }}\end{array}$ \\
\hline $\begin{array}{l}\text { Terrestrial eutrophication (kg wood) } \\
\text { Land Use (PDF } \mathrm{m}^{\angle} \text { year } / \mathrm{m}^{2} \text { ) } \\
\text { Non-fossil and fossil abiotic resources depletion (kg antimony eq) }\end{array}$ & $\begin{array}{l}6 \cdot 0837610^{\perp U} \\
1 \cdot 5000610^{\perp<} \\
1 \cdot 5000610^{\perp U}\end{array}$ & $\begin{array}{l}\text { EU-15, } 1996^{* *} \\
\text { Western Europe, } 1995^{50,3 /} \\
\text { Western Europe, } 1995^{50,3 /}\end{array}$ \\
\hline
\end{tabular}

*DALY: disable adjust life years.

\{YOLL: years of life lost.

\{Global warming emissions in EU-15, 1995, totalled 3269734 011?3 Mg in CO2, 19519909 ?6 Mg in CH4 and 1209211 ?5 Mg in $\mathrm{N}_{2} \mathrm{O} .40$

1Photo-oxjdant formation emissions in EU-15, 1995, totalled 11596281 ?1 Mg in NOx (EEA, 2006a) and 13736000 Mg in NMVOC. ${ }^{4}$

"Acidifying emissions in EU-15, 1995, totalled 11596 281?1 Mg in NOx, 1209 211?5 Mg in N2O, 10073020 ? Mg in SO2

and 315508 ? $8 \mathrm{Mg}$ in $\mathrm{NH}_{3}{ }^{40}$

**Terrestrial eutrophication emissions in EU-15, 1995, totalled 11596 281?1 Mg in NOx, 1209 211?5 Mg in N2O and 3315508 ? $\mathrm{Mg}$ in $\mathrm{NH}_{3} .40$

normalised PEI categories can then be all summed or aggregated in just one indicator or total PEI. No weighting set was considered in the present study.

\section{Comparison of allocation approaches}

In this study, the influence of using the mass, energy or economic based allocations is analysed at four levels:

(i) normalised PEI categories $N_{\mathrm{k}}$

(ii) total PEI

(iii) relative contribution of each $N_{k}$ category to total PEl, obtained by dividing $N_{\mathrm{k}}$ by the total PEI

(iv) relative contribution of each life cycle stage to total PEI, obtained by dividing the PEI of each life cycle stage by the total PEI.

Environmental impact assessment

Table 5 shows the normalised PEl categories $N_{k} 1, N_{k} 2$ and $N_{\mathrm{k} 3}$ for the mass, energy, and economic based allocations respectively, which are summed or aggregated in order to obtain the total PEl. The normalised $\mathrm{PEI}$ were further compared with the mass based allocation, by dividing each normalised PEI category of the three allocation approaches $N_{\mathrm{k} 1}, N_{\mathrm{k} 2}$ and $N_{\mathrm{k} 3}$ by each normalised PEI category of the mass based allocation $N_{\mathrm{k} 1}$, represented as $R 1, R 2$ and $R 3$ in Table 5 . Table 5 shows similar normalised PEI results for the economic and energy based allocations, although they significantly differ from the mass based allocation. In particular, they are lower for each category considered, and the differences can be as high to 2?68 times lower for the land use impact category. In addition, the total PEI of the economic and energy based allocations is $\boldsymbol{y} 1$ ?50 higher than the mass based allocation.

Economic based allocation sensitivity analysisAmong other aspects, the price data used for the study may influence results. For this reason a sensitivity analysis is performed considering two potential market scenarios: $50 \%$ decrease of glycerol price due to oversupply and $50 \%$ increase of soybean oil price due to increase of biodiesel demand.

In the first scenario, the total PEI is up to 1 ?55 higher for the economic based allocation in comparison to the mass based allocation, and it is up to 1 ?68 higher in the second scenario. These results illustrate that the price volatility is a main disadvantage of using the economic

Table 5 Normalised PEl categories for three allocation approaches $N_{\mathrm{k} 1}, N_{\mathrm{k} 2}$ and $N_{\mathrm{k} 3}$, respective of total PEl, and their comparison with mass based allocations $R 1, R 2$ and $R 3$

\begin{tabular}{|c|c|c|c|c|c|c|}
\hline Normalised PEI category (dimensionless) & $\begin{array}{l}\text { Nk1 (mass } \\
\text { based } \\
\text { allocation) }\end{array}$ & $R 1$ & $\begin{array}{l}\text { Nk2 (energy } \\
\text { based allocation) }\end{array}$ & $R 2$ & $\begin{array}{l}N \mathrm{k} 3 \text { (economic } \\
\text { based } \\
\text { allocation) }\end{array}$ & R3 \\
\hline Global warming & $3.00610^{214}$ & $1 \cdot 00$ & $4 \cdot 86610^{214}$ & 1.62 & $5.06610^{214}$ & 1.68 \\
\hline Stratospheric ozone depletion & $4.57610<10$ & $1 \cdot 00$ & $5 \cdot 19610<10$ & $1 \cdot 14$ & $5 \cdot 25610<10$ & $1 \cdot 15$ \\
\hline $\begin{array}{l}\text { Carcinogenic and Non-carcinogenic human } \\
\text { toxicological effects }\end{array}$ & $2 \cdot 34610^{<14}$ & $1 \cdot 00$ & $2 \cdot 83610<14$ & $1 \cdot 21$ & $2 \cdot 90610<14$ & $1 \cdot 24$ \\
\hline Photo-oxidant formation & $2 \cdot 15610^{216}$ & $1 \cdot 00$ & $2 \cdot 28610^{216}$ & 1.06 & $2 \cdot 29610^{216}$ & $1 \cdot 06$ \\
\hline Freshwater aquatic ecotoxicity & $2 \cdot 30610<15$ & $1 \cdot 00$ & $3.03610<13$ & $1 \cdot 32$ & $3 \cdot 13610<13$ & $1 \cdot 36$ \\
\hline Marine aquatic ecotoxicity & $8.67610<14$ & $1 \cdot 00$ & $1 \cdot 14610<13$ & $1 \cdot 32$ & $1 \cdot 18610<13$ & $1 \cdot 36$ \\
\hline Terrestrial ecotoxicity & $6 \cdot 77610<\perp y$ & $1 \cdot 00$ & $1.08610^{<\perp ర}$ & $1 \cdot 59$ & $1 \cdot 12610^{<\perp ర}$ & 1.66 \\
\hline Acidification & $1 \cdot 21610^{<13}$ & $1 \cdot 00$ & $1.56610^{<13}$ & $1 \cdot 29$ & $1 \cdot 60610^{<13}$ & $1 \cdot 33$ \\
\hline Aquatic eutrophication & $2 \cdot 75610<1 /$ & 1.00 & $5 \cdot 16610<1 /$ & $1 \cdot 87$ & $5 \cdot 36610<\perp$ & 1.95 \\
\hline Terrestrial eutrophication & $8 \cdot 86610<14$ & $1 \cdot 00$ & $1 \cdot 10610^{<13}$ & $1 \cdot 24$ & $1 \cdot 12610^{<13}$ & $1 \cdot 26$ \\
\hline Land use & $4 \cdot 64610<14$ & $1 \cdot 00$ & $1 \cdot 18610^{<13}$ & $2 \cdot 55$ & $1 \cdot 24610^{<13}$ & $2 \cdot 68$ \\
\hline Non-fossil and fossil abiotic resources & $2 \cdot 72610<14$ & $1 \cdot 00$ & $4 \cdot 04610<14$ & $1 \cdot 49$ & $4 \cdot 20610<14$ & $1 \cdot 55$ \\
\hline TotalPEI & $4 \cdot 26610<13$ & $1 \cdot 00$ & $6 \cdot 19610<13$ & $1 \cdot 45$ & $6 \cdot 39610<13$ & $1 \cdot 50$ \\
\hline
\end{tabular}


Table 6 Relative contribution of each normalised impact category to total PEI, comparing three allocation approaches

\begin{tabular}{lrcr}
\hline PEI category, \% & Mass based allocation & Energy based allocation & Economic based allocation \\
& & & \\
\hline Global warming & $7 \cdot 05$ & $7 \cdot 85$ & $7 \cdot 91$ \\
Stratospheric ozone depletion & $0 \cdot 11$ & $0 \cdot 08$ & $0 \cdot 08$ \\
Human toxicological effects & $5 \cdot 50$ & $4 \cdot 57$ & $4 \cdot 53$ \\
Photo-oxidant formation & $0 \cdot 05$ & $0 \cdot 04$ & 0.04 \\
Freshwater aquatic ecotoxicity & $0 \cdot 54$ & $0 \cdot 49$ & $0 \cdot 49$ \\
Marine aquatic ecotoxicity & $20 \cdot 36$ & $18 \cdot 46$ & $18 \cdot 41$ \\
Terrestrial ecotoxicity & $0 \cdot 00$ & $0 \cdot 00$ & $0 \cdot 00$ \\
Acidification & $28 \cdot 33$ & $25 \cdot 15$ & $25 \cdot 08$ \\
Aquatic eutrophication & $0 \cdot 01$ & $0 \cdot 01$ & 0.01 \\
Terrestrial eutrophication & $20 \cdot 80$ & $17 \cdot 71$ & $17 \cdot 48$ \\
Land use & $10 \cdot 88$ & $19 \cdot 10$ & $19 \cdot 40$ \\
Abiotic resources depletion & $6 \cdot 38$ & $6 \cdot 53$ & $6 \cdot 57$ \\
\hline
\end{tabular}

based allocation approach considering the timeframe of a LCA study.

Relative contributions to total PEI

Table 6 shows the relative contributions of each normalised impact category to the total $\mathrm{PEI}$, comparing the mass, energy and economic based allocations. The comparison between these relative contributions for the three allocation approaches shows small differences among them.

Table 7 shows the relative contributions to the total PEI of each life cycle stage.

Significant differences are observed between the mass based allocation and the other approaches than between the energy and economic based allocations. This is expected due to the differences observed in Table 2 for the allocation factors of the soybean oil extraction process. For example, in the case of the economic and energy based allocation approaches, soybean agriculture is the second most important life cycle stage in a PEI basis, while the application of a mass based allocation shows that this life cycle stage is of relative low significance to the overall environmental impacts.

Criteria on selection of allocation approach

The authors of case studies and generic guidelines appear to be in search of a single allocation approach to be generically applied. An alternative view proposes that the goal should be to find the appropriate allocation basis for a particular process or type of process and apply it consistently, rather than trying to decide on one allocation method to use in all cases. ${ }^{42,43}$ In this alternative perspective, it is observed in the results presented in Table 4 that mass allocation applied to both multi-output processes assign the minimum envir- onmental burdens to biodiesel life cycle; in opposite, economic allocation applied to both multi-output processes assign the maximum environmental burdens. Other combinations would show intermediary results. In this trend, whichever view is adopted (a single allocation approach for all processes or specific allocation approaches for particular processes), the soybean biodiesel LCA overall environmental impacts may range

from a factor of 1 ? 00 to 1 ? 50 for the present case.

The literature fails to identify a logically defensible approach for allocation. What continues to be lacking is a unifying theory that can explain what allocation basis is justifiable in any given situation. ${ }^{2}$ Weidema and Norris 44 presented general guidelines to choose an allocation approach. The authors state that physical allocation, e.g. mass or energy based allocation, is justifiable in coproduction when the coproduct amount is actually determining the volume flows of the coproducing process, i.e. an increase in the output of a specific coproduct causes an increase in production in direct proportion. This is especially applicable in soy biodiesel life cycle where the amounts of the individual coproducts are interdependent in a physical relationship: a production increase in soybean meal or in glycerol (biodiesel life cycle coproducts) results in a production increase of soybean oil or soy biodiesel. Similarly, they apply this logic to economic allocation, which is a justifiable approach when the volume of the coprodu- cing process varies in proportion to the changes in economic revenue to the process from the different coproducts. For the biodiesel life cycle, an increase of soybean meal price may lead to an increase of soybean production, but it does not lead to a variation in the proportion of coproducts.

According to these criteria, mass or energy based allocation approaches should be applied in biodiesel life cycle, although the choice between both approaches remains arbitrary. Considering the results of the present study, such arbitrary choice produces diverging results and eventually misleading conclusions and misdirected decision making. One can argue that energy based allocation should only be applied when the function of

Table 7 Relative contribution of each life cycle stage to total PEI, comparing mass, energy and economic based allocations

\begin{tabular}{|c|c|c|c|}
\hline Life cycle stage & $\begin{array}{l}\text { Mass based } \\
\text { allocation, } \\
\% \text { total PEI }\end{array}$ & $\begin{array}{l}\text { Energy based } \\
\text { allocation, } \\
\text { \% total PEI }\end{array}$ & $\begin{array}{l}\text { Economic based allocation, } \\
\% \text { total PEI }\end{array}$ \\
\hline Soybean agriculture & $13 \cdot 87$ & $24 \cdot 73$ & $25 \cdot 13$ \\
\hline Soybean seeds transportation & $4 \cdot 26$ & $7 \cdot 60$ & $7 \cdot 72$ \\
\hline Soybean oil extraction & $9 \cdot 03$ & $15 \cdot 96$ & $16 \cdot 22$ \\
\hline Biodiesel production & $34 \cdot 05$ & $25 \cdot 00$ & $25 \cdot 08$ \\
\hline Biodiesel transportation & $18 \cdot 08$ & $12 \cdot 45$ & $12 \cdot 05$ \\
\hline Biodiesel use & $20 \cdot 71$ & $14 \cdot 26$ & $13 \cdot 80$ \\
\hline
\end{tabular}


all coproducts is strictly to serve as a fuel, since considering the energy based allocation in a food context (e.g. soybean meal) may not be appropriate. In this case, the function of coproducts is determining for the choice between mass and energy based allocation approach, and mass allocation would be the appropriate allocation approach in biodiesel life cycle for both multi- output processes. Another question arises when a shift of function of a given coproduct is observed. For example, if glycerol is to be used as a fuel due to oversupply and energy based allocation is used instead of mass allocation, the allocation factor for the biodiesel main product will be higher leading to higher environ- mental burdens to be allocated to biodiesel main product (Table 4). This eventually leads to constraints in the glycerol reuse based in a pure LCA methodolo- gical criteria and not in a real environmental standpoint.

\section{Conclusions}

Results of LCA not only depend on the system boundary assumptions but also on the allocation approaches chosen to model the inventory analysis. This study shows that similar results are obtained when comparing the economic and energy based allocations, but different results are obtained for the mass based allocation. These differences could be critical in some comparative LCA studies, producing misleading con- clusions and misdirected decision making.

In this LCA study, the mass based allocation applied to both multi-output processes (soybean oil extraction and biodiesel production) assigned the lowest total PEI to the soybean biodiesel life cycle, while the economic and energy based allocations assigned the highest total $\mathrm{PEI}$, i.e. up to 1?50 higher than for the mass based allocation. Moreover, the relative contributions of each life cycle stage to the total PEI are significantly different for mass based relatively to the energy and economic based allocations. However, no significant difference is observed for the relative contributions of each impact category to the total PEI among the three allocation approaches.

\section{References}

1. 'Draft guidance on apportioning of project emissions to co- products and by-products in biofuel production', 31st meeting report, Annex 7, UNFCCC, Vienna, Austria, November 2007, 1-5.

2. M. A. Curran: Environ. Sci Technol., 2007, 41, 7145-7151.

3. 'Life cycle assessment: inventory guidelines and principles', EPA/ 600/R-92/245; US Environmental Protection Agency, Washington, DC, USA, 1993.

4. M. Wang: 'The greenhouse gases, regulated emissions, and energy use in transportation (GREET) model, version 1.5'; Argonne National Laboratory, Department of Energy, Chicago, IL, USA, 1999.

5. J. Guine'e, R. Heijungs and G. Huppes: Int. J. Life Cycle Assess., 2004, 9, (1), 23-33.

6. B. Weidema: J. Ind. Ecol., 2000, 4, 11-33.

7. 'Environmental management - life cycle assessment goal and scope definition - inventory analysis', ISO 14041, International Standard Organization, Geneva, Switzerland, 1998.

8. S. Kim and B. E. Dale: Int. J. Life Cycle Assess., 2002, 7, (4), 237-243.

9. A. E. Farrell, R. J. Plevin, B. T. Turner, A. D. Jones, M. O'Hare and D. M. Kammen: Science, 2006, 311, (5760),
506-508.

10. A. Pradhan, D. S. Shrestha, J. van Gerpen and J. Duffield: Trans. ASABE, 2008, 51, (1), 185-194.

11. J. Sheehan, J. Duffield, M. Graboski and H. Shapouri: 'Life cycle inventory of biodiesel and petroleum diesel for use in an urban bus'; 1998, Golden, CO, NREL. 
12. M. A. Elasayed, R. Matthews and N. D. Mortimer: 'Carbon and energy balances for a range of biofuel options'; 2003, Sheffield, Sheffield Hallam University.

13. R. Zah, H. Bo" ni, M. Gauch, R. Hischier, M. Lehmann, P. Wa" ger: 'Life cycle assessment of energy products: environmental assess- ment of biofuels'; 2007, Bern, Empa.

14. J. Hill, E. Nelson, D. Tilman, S. Polasky and D. Tifanny: Proc. Natl Acad. Sci. USA, 2006, 103, (30), 11206-11210.

15. S. Bernesson, D. Nilsson and P. A. Hansson: Biomass Bioenergy, 2004, 26, 545-559.

16. H. Huo, M. Wang, C. Bloyd and V. Putsche: 'Life-cycle assessment of energy and greenhouse gas effects of soybean-derived biodiesel and renewable fuels', ANL/ESD/08-2, Argonne National Laboratory, Argonne, IL, USA, 2008.

17. J. Guine'e: 'Handbook on life cycle assessment: operational guide to the ISO standard'; 2002, Dordrecht, Kluwer Academic Publishing.

18. R. Frischknecht, H.-J. Althaus, C. Bauer, G. Doka, T. Heck,

N. Jungbluth, D. Kellenberger and T. Nemecek: Int. J. Life Cycle Assess. Spec. Issue, 2007, 12, (1), 7-17.

19. R. Frischknecht: 'O ko-inventare von Energiesystemen', 3th edn; 1996, Bern, ENET.

20. 'O" koinventare fü $r$ Verpackungen', Schriftenreihe Umwelt 250, BUWAL, Bern, Switzerland, 1996.

21. T. Beer, T. Grant, G. Morgan, J. Lapszewicz, P. Anyon, J. Edwards, P. Nelson, H. Watson and D. Williams: 'Comparison of transport fuels: stage 2 study of life-cycle emissions analysis of alternative fuels for heavy vehicles'; 2002, Aspendale, CSIRO Atmospheric Research and Australian Greenhouse Office.

22. H. Shapouri, M. Wang and J. Duffield: 'Net energy balance and fuel-cycle analysis', in 'Renewables-based technology' (ed.

J. Dewulf and H. van Langenhove), 73-86; 2006, Chichester, John Wiley and Sons.

23. H. Shapouri, J. A. Duffield, M. S. Graboski: 'Estimating the net energy balance of corn ethanol: an economic research service report', Agricultural economic report no. 721, US Department of Agriculture, Washington, DC, USA, 1995.

24. G. N. Lodhi, R. Renner and D. R. Clandinin: J. Nutr., 1969, 99, 413418.

25. A. Altin, S. C, etinkaya and H. S. Yü cesu: Energy Convers. Manag., 2001, 42, (5), 529-538.

26. 'Biodiesel, barriers, potentials and impacts', Energy Systems Research Unit (ESRU), University of Strathclyde, 2007 available

at: http://www.esru.strath.ac.uk/EandE/Web_sites/0607/Biodiesel/ experiment.htm (accessed on 23 March 2009).

27. J. T. Houghton, Y. Ding, D. J. Griggs, M. Noguer, P. J. van der Linden and D. Xiaosu (eds.): in 'Climate change 2001: the scientific basis', 'Contribution of Working Group I to the third assessment report of the Intergovernmental Panel on Climate Change (IPCC)'; 2001, Cambridge, Cambridge University Press.

28. 'Scientific assessment of ozone depletion: 2002', GORaM project, Report no. 47, World Meteorological Organization, Geneva, Switzerland, 2002.

29. M. A. J. Huijbregts, J. S. M. Goedkoop, R. Heijungs and D. Meent:
Chemosphere, 2005, 61, 1495-1504.

30. M. A. J. Huijbregts, L. J. A. Rombouts, M. J. Ragas and D. Meent:

Integr. Environ. Assess. Manag., 2005, 1, (3): 181-244.

31. W. Krewitt, A. Trukenmu" Iler, T. M. Bachmann and T. Heck: Int. J. Life Cycle Assess., 2001, 6, (4), 199-210.

32. M. A. J. Huijbregts, U. Thissen, J. Guine'e, T. Jager, D. Kalf and

D. Meent: Chemosphere, 2000, 41,541-573.

33. B. Steen: 'A systematic approach to environmental priority strategies in product development (EPS), version 2000 - models and data of the default method'; 1999, Go"teborg, Chalmers University.

34. B. Steen: 'A systematic approach to Environmental Priority Strategies in product development (EPS), version 2000 - general system characteristics'; 1999, Go"teborg, Chalmers University.

35. M. A. J. Huijbregts, W. Scho“ pp, E. Verkuijlen, R. Heijungs and L. Reijnders: J. Ind. Ecol., 2000, 4, (3), 125-142.

36. M. Goedkoop and R. Spriensma: 'The eco-indicator 99. A damage oriented method for life cycle impact assessment - methodology report'; 1999, Amersfoort, PRe' Consultants.

37. M. Goedkoop and R. Spriensma: 'The eco-indicator 99. A damage oriented method for life cycle impact assessment - methodology annex', 3th edn; 2001, PRe' Consultants

38. D. W. Pennington, J. Potting, G. Finnveden, E. Lindeijer, O. Jolliet and G. Rebitzer: Environ. Int., 2004, 30, 721739.

39. M. A. J. Huijbregts, L. Breedveld, G. Huppes, A. Koning, L. Oers and S. Suh: J. Clean Prod., 2003, 11, 737-748.

40. 'Air emission data set for indicators', Environmental European Agency, 2006, available at: http://dataservice.eea.europa.eu/ dataservice/metadetails.asp?id5818 (accessed on 23 March 2009). 
41. 'Indicator fact sheet signals 2001 - chapter air pollution', Environ- mental European Agency, 2006, available at: http://themes.eea. europa.eu/Specific_media/air/indicators/particulates/y ir99ap4.pdf (accessed on 23 March 2009).

42. N. W. Ayer, P. H. Tyedmers, L. Nathan, N. L. Pelletier, U. Sonesson and A. Scholz: Int. J. Life Cycle Assess., 2007, $12,(7), 480-487$.
43. M. A. Curran: in 'Development of life cycle assessment methodol- ogy: a focus on co-product allocation', PhD thesis, Erasmus Universiteit Rotterdam, Rotterdam, The Netherlands, 2008.

44. B. Weidema and G. Norris: 'Avoiding co-product allocation in the metals sector', Proc. ICMM Int. Workshop on 'Life cycle assessment and metals', Montreal, Canada, April 2002, ICMM, 81-87. 